\title{
Parvalbumin Is Reduced in the Peripheral Nerves of Diabetic Rats
}

\author{
Toyoshi Endo and Toshimasa Onaya \\ The Third Department of Internal Medicine, University of Yamanashi Medical School, Tamaho, Yamanashi-ken 409-38, Japan
}

\begin{abstract}
Parvalbumin (PA), one of the $\mathrm{Ca}^{2+}$-binding neuronal marker proteins, has been revealed to exist in the myelinated axons of the posterior root of the spinal cord and the peripheral nerve of rats. To investigate the role of PA for the genesis of diabetic neuropathy, the levels of PA in the sciatic nerve of normal and streptozotocin-induced diabetic rats were measured by radioimmunoassay (RIA) for PA. The immunohistochemical distribution of PA in the sciatic nerve from both groups was also studied. The RIA for PA revealed that the levels of PA in the sciatic nerve of diabetic rats were significantly decreased when compared with those of normal rats. However, the contents of S-100 protein, another type of $\mathrm{Ca}^{2+}$-binding glial marker protein, did not show any significant difference in the sciatic nerve from both groups. Immunohistochemically, the amount of PA containing myelinated axons of the diabetic nerve was markedly decreased when compared with nondiabetic subjects. These results suggest that the decreased level of PA in the peripheral nerve might contribute to the genesis of diabetic neuropathy.
\end{abstract}

\section{Introduction}

$\mathrm{Ca}^{2+}$ is involved in many biological functions and requires the presence of specific intracellular $\mathrm{Ca}^{2+}$-binding proteins to exert its regulatory roles $(1,2)$. In the diabetic nervous system, it is known that some disturbance of $\mathrm{Ca}^{2+}$-dependent functions such as axonal transport or cell excitability exists (3-5). Thus, $\mathrm{Ca}^{2+}$ has been considered an important factor in clarifying the pathogenesis of diabetic neuropathy. However, the molecular basis of such a disturbance remains unclear.

Two different $\mathrm{Ca}^{2+}$-binding proteins exist in the nervous tissues, namely parvalbumin (PA) ${ }^{1}$ and S-100 protein (S-100).

PA was found in type IIB skeletal muscle fibers (6). The relaxing speed of these muscle fibers increased linearly with the concentrations of this protein. Thus PA is regarded as a relaxing factor of the skeletal muscle (7). In describing the central nervous system, Celio and Heizmann suggested that PA was a marker of a distinct subpopulation of neurons such as Purkinje neurons of the cerebellum and nonpyramidal neurons of the cerebrum (8).

$\mathrm{S}-100$ is a nervous tissue-specific protein that is mainly located in astrocytes of the central nervous tissues and in Schwann

Address correspondence to Dr. Endo.

Received for publication 7 July 1986.

1. Abbreviations used in this paper: PA, parvalbumin; S-100, S-100 protein; Sciatic N., sciatic nerve; STZ, streptozotocin.

J. Clin. Invest.

(C) The American Society for Clinical Investigation, Inc.

$0021-9738 / 86 / 11 / 1161 / 04 \$ 1.00$

Volume 78, November 1986, 1161-1164 cells in the peripheral nerve $(9,10)$. Although the exact biological function of S-100 remains unknown, it may play a role in microtubule assembly (11) and contribute to the maturation of glial elements (12).

We previously reported rapid purification procedures for PA and S-100 $(13,14)$ and developed sensitive assay systems for these proteins using specific antiserum against rat skeletal muscle PA and bovine brain S-100 $(15,16)$.

In the present study, we measured the levels of PA and S-100 in the peripheral nerves of normal and diabetic rats to clarify the role of $\mathrm{Ca}^{2+}$-binding proteins for the genesis of diabetic neuropathy. We also used immunohistochemical methods to analyze the distributions of PA containing axon in the peripheral nerves.

\section{Methods}

Animals. Diabetes mellitus was induced in $250-300-\mathrm{g}$ male Wistar rats with a peritoneal injection of $50 \mathrm{mg} / \mathrm{kg}$ streptozotocin (STZ) dissolved in $0.1 \mathrm{M}$ citrate buffer. Control rats were sham injected with the buffer alone. Rats were fed standard chow and allowed free access to water. The blood glucose concentration (nonfasting) was measured in the blood obtained by cardiac puncture.

Preparation of rat skeletal muscle $P A$ and bovine brain $S-100 b$ and the production of their antiserum. Rat skeletal muscle PA and bovine brain S-100b were purified by the methods previously described $(13,14)$. Antisera to rat skeletal muscle PA and bovine brain S-100b were raised
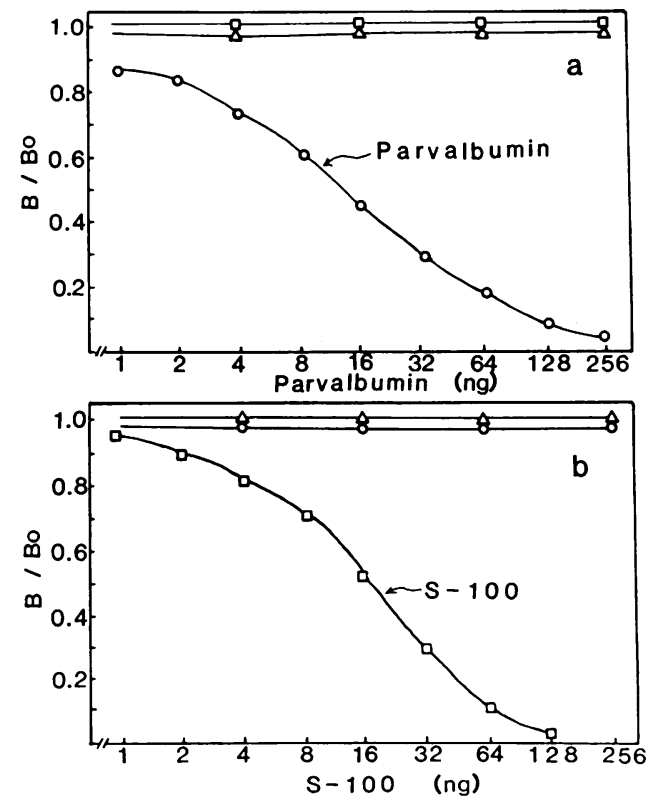

Figure 1. Standard curves of the RIA for PA and S-100 standard curve of the RIA for PA (a) and S-100 (b). (o) Rat skeletal muscle PA. (口) bovine brain $\mathrm{S}-100 ;(\Delta)$ bovine brain calmodulin. In both assays, cross-reactivity between PA and S-100 or calmodulin has not been observed. 


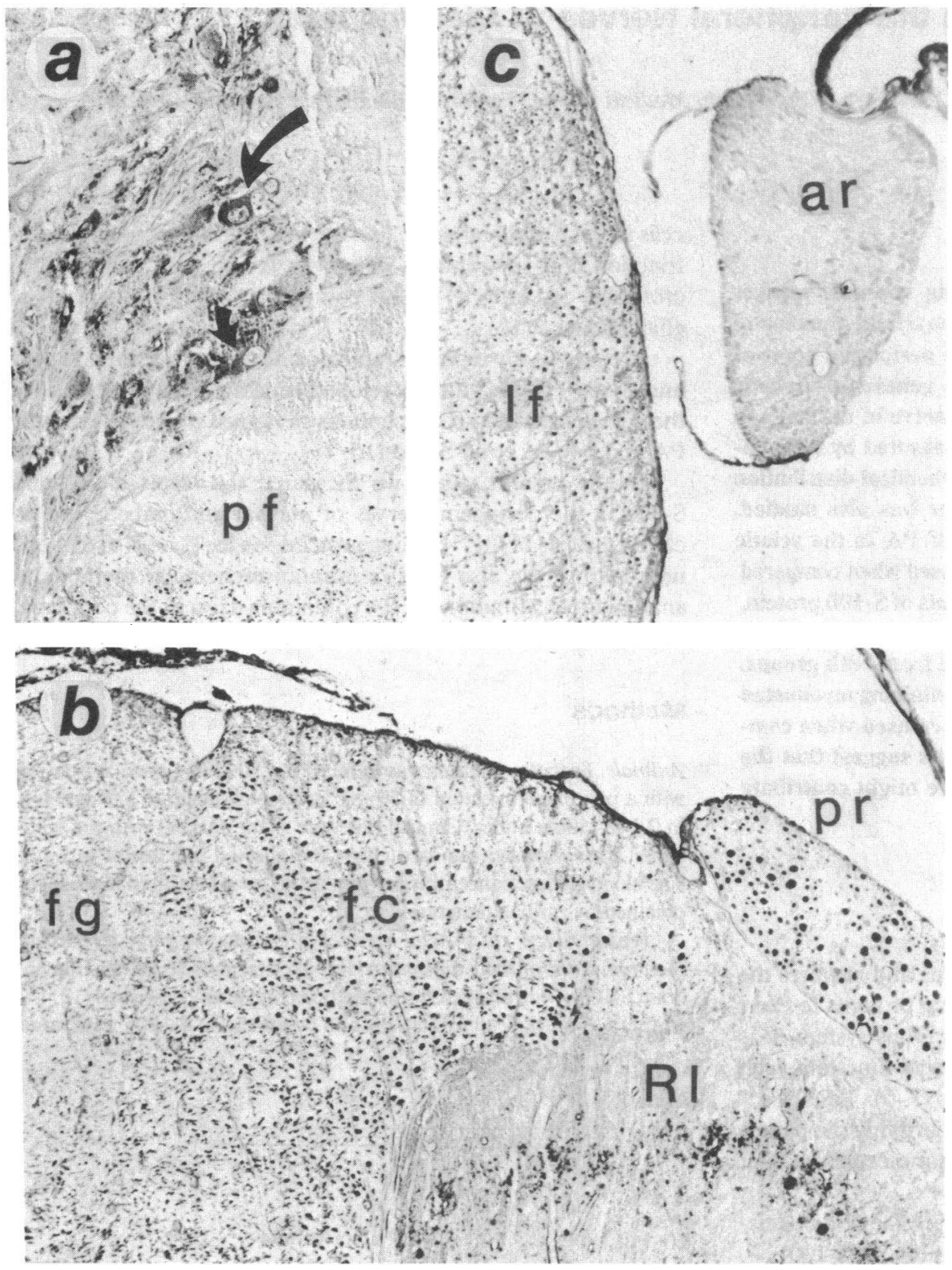

Figure 2. Photomicrographs showing the distribution of PA immunoreactivity in rat spinal cord. (a) Posterior horn of the spinal cord. (Arrow) PA-containing neurons that located close to the ventral aspects of the posterior funiculus $(p f) .(\times 200)$. (b) Dorsal aspect of the spinal cord. PA-positive axons are observed at Rexed lamina II $(R l)$, fasciculus cuneatus $(f c)$, and posterior root $(p r)$ $(\times 100) . f g$, fasciculus gracilis. $(c)$ Anterior root of the spinal cord. No PA immunoreactivity is seen in the anterior root $(a r)$. lf, lateral funiculi. $(\times 100)$.

in rabbits. The specificity of the antisera to PA and S-100 has been published elsewhere (15-18).

Radioimmunoassay (RIA) for PA and S-100. The RIA for PA was performed as described previously (15). The RIA for S-100 was carried out essentially by the same procedures as those for PA. In brief, bovine brain S-100b was iodinated with Bolton-Hunter reagent, which produced ${ }^{125}$ I-labeled S- $100 \mathrm{~b}$ with a specific radioactivity of $504 \mathrm{Ci} / \mathrm{mmol}$. RIA of S-100b was carried out in $0.4 \mathrm{ml}$ of RIA buffer $(0.125 \mathrm{M}$ borate buffer containing $1 \mathrm{mM}$ EGTA, $75 \mathrm{mM} \mathrm{NaCl}, 0.5 \%$ (wt/vol) bovine serum albumin, $\mathrm{pH} 8.4)$, which contained a fixed amount of ${ }^{125} \mathrm{I}-\mathrm{S} 100 \mathrm{~b}\left(2 \times 10^{4}\right.$ $\mathrm{cpm}), 0.0132 \mu \mathrm{g}$ of Anti-S100b IgG, and extract from tissues. After overnight incubation at $4^{\circ} \mathrm{C}, 30 \mu \mathrm{l}$ of RIA-gnost ${ }^{-}$(Hoechst-Roussel Pharmaceuticals, Inc., Somerville, NJ) was added and the mixture was incubated at $25^{\circ} \mathrm{C}$ for $30 \mathrm{~min}$. Then, the mixture was centrifuged at $3,000 \mathrm{rpm}$ for $10 \mathrm{~min}$, and the resultant pellet was washed with RIA buffer three times. Radioactivity of the final pellet was determined with Aloka-gamma-counter.

Preparation of tissue extract was performed as follows: The sciatic nerves (Sciatic N.) were quickly removed from the rats after decapitation. The tissues were immediately heated at $85^{\circ} \mathrm{C}$ for $3 \mathrm{~min}$ in a borate buffer, and homogenized with a glass-Teflon homogenizer. Insoluble material was removed by centrifugation at $3,000 \mathrm{rpm}$ for $10 \mathrm{~min}$, and the supernatant solution was used for the assay. The sensitivity and crossreactivity of the RIA for PA and S-100 is shown in Fig. 1.

Immunohistochemistry. For immunohistochemistry, normal and diabetic Wistar rats, anesthetized with Nembutal, were fixed by intra-aortic perfusion with Bouin's fluid, dehydrated in a graded ethanol series, and embedded in paraffin. 5- $\mu \mathrm{m}$-thick sections were washed in a phosphatebuffered saline (PBS) and treated with normal goat serum (Miles Laboratories, Inc., Elkhart, IN) for $30 \mathrm{~min}$. After washing in PBS, the sections were incubated with the anti-PA serum $(1: 1,000)$ or anti-S 100 serum (1:500) for $12 \mathrm{~h}$ at $4^{\circ} \mathrm{C}$, rinsed in PBS, and incubated with goat antirabbit IgG (1:200) (Miles Laboratories, Inc.) for $30 \mathrm{~min}$. The sections were washed in PBS and incubated with peroxidase antiperoxidase complex (1:200) (Miles Laboratories, Inc.). After washing, the enzyme reaction was developed with diaminobenzidine- $\mathrm{H}_{2} \mathrm{O}_{2}(19)$.

\section{Results}

Immunohistochemical localization of $P A$ in the spinal cord of normal rats. In the spinal cord of the normal rat, a group of 
large immunoreactive neurons was located close to the ventral aspects of the posterior funiculus (Fig. $2 a$ ), and PA-containing fibers were observed in Rexed lamina II (Fig. $2 b$ ). In the white matter, PÁ-positive myelinated axons were observed in anterior funiculus and lateral funiculus (Fig. $2 c$ ). In posterior funiculus, the axons in the fasciculus cuneatus contained PA, but we could not detect PA immunoreactivity in the fasciculus gracilis (Fig. $2 \mathrm{~b}$ ). Note that PA-positive myelinated axons exist in the posterior root (Fig. $2 b$ ), but no immunoreactivity was seen in the anterior root (Fig. 2 c). This suggests that PA-containing fiber might be correlated with sensory nerve.

The contents of $P A$ in the peripheral nerve of normal and $S T Z$-induced diabetic rats. Blood glucose concentrations (nonfasting) of the rats from the different protocols are shown in Table I. The blood glucose concentrations averaged $288 \pm 46 \mathrm{mg} /$ $\mathrm{dl}$ at $20 \mathrm{~d}$ after STZ and $351 \pm 65 \mathrm{mg} / \mathrm{dl}$ at $40 \mathrm{~d}$ after STZ versus $144 \pm 9 \mathrm{mg} / \mathrm{dl}$ in control $(P<0.05)$.

In these conditions, the contents of PA and S-100 in the Sciatic N. from normal and STZ-induced diabetic rats were measured by RIA. The levels of PA in the diabetic Sciatic N. at $20 \mathrm{~d}$ after STZ was $112 \pm 38 \mathrm{ng} / \mathrm{mg}$ protein. The values were significantly lower than corresponding values in control animals
Table I. Blood Sugar and the Contents of Parvalbumin and S-100 in the Sciatic Nerve of the Normal and Stretozotocin-induced Diabetic Rats

\begin{tabular}{llll}
\hline Group & Blood sugar & $\begin{array}{l}\text { PA contents } \\
\text { in Sciatic N. }\end{array}$ & $\begin{array}{l}\text { S-100 contents } \\
\text { in Sciatic N. }\end{array}$ \\
\hline & $m g / d l$ & $n g / m g$ protein & $n g / m g$ protein \\
Control* $^{*}$ & $144 \pm 9$ & $263 \pm 44$ & $367 \pm 84$ \\
DM $(20 \mathrm{~d}) \ddagger$ & $288 \pm 46 \S$ & $112 \pm 38 \S$ & $363 \pm 83$ \\
DM $(40 \mathrm{~d})^{\prime \prime}$ & $351 \pm 65 \S$ & $20 \pm 5 \pi$ & $451 \pm 95$ \\
\hline
\end{tabular}

* Nondiabetic rats at $20 \mathrm{~d}$.

$¥$ STZ-induced diabetic rats at $20 \mathrm{~d}$.

$\S P<0.05$.

"STZ-induced diabetic rats at $40 \mathrm{~d}$.

I $P<0.01$.

(Table I). The contents of PA in the diabetic Sciatic N. further decreased as a function of time, to $20 \pm 5 \mathrm{ng} / \mathrm{mg}$ protein at $40 \mathrm{~d}$ after STZ.

On the other hand, no significant difference was observed in the contents of S-100 in the Sciatic N., when diabetic and normal subjects were compared (Table I).

Immunohistochemical localization of $P A$ in the normal and
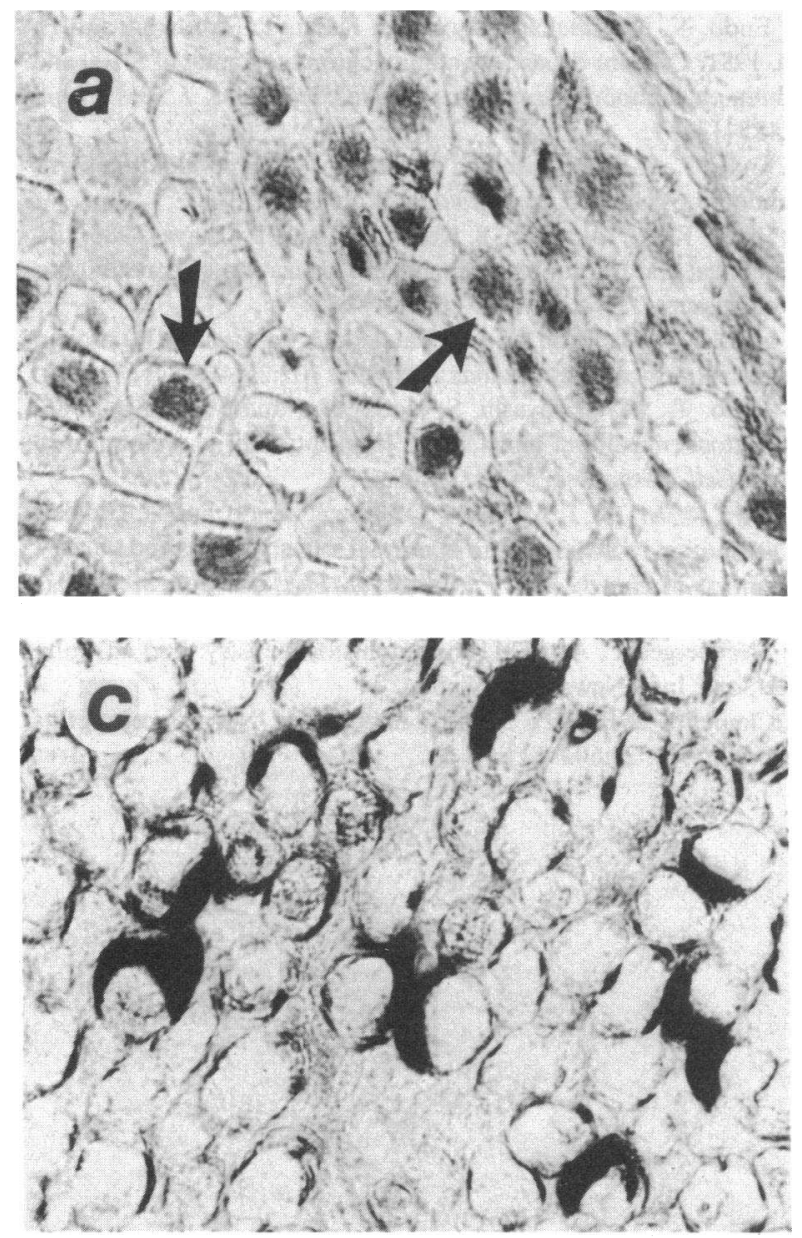

Figure 3. Immunohistochemical distribution of PA and S-100 in the normal and diabetic Sciatic N. (a) PA immunoreactivity of the cross sections of the Sciatic N. from control rat. Some but not all myelinated axons are heavily stained with the antiserum to PA (arrows). ( $X$ 400). (b) PA immunoreactivity of the cross sections of the Sciatic N. from diabetic rat ( $40 \mathrm{~d}$ after STZ). PA-positive fibers were rare. $(X$
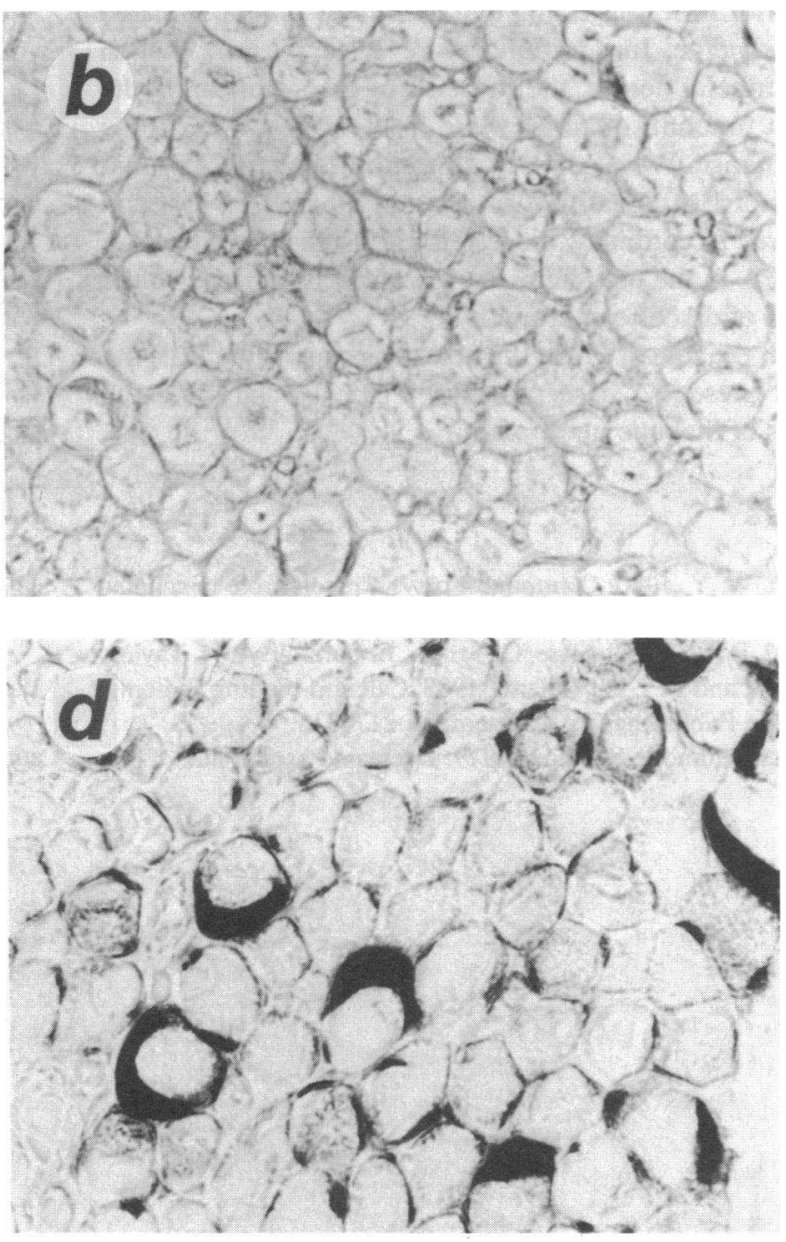

400). (c) S-100 immunoreactivity of the cross sections of the Sciatic N. from control rat. Schwann cells are heavily stained with antisera to $S$ 100. $(\times 400)$. (d) S-100 immunoreactivity of the cross sections of the Sciatic N. from diabetic rats. Schwann cells are also labeled with the antiserum. $(\times 400)$. 
diabetic Sciatic $N$. Fig. 3 a shows the PA immunoreactivity in the Sciatic N. of normal rats. Some but not all myelinated axons were heavily stained with antiserum to parvalbumin. The rare appearance of PA positive fibers in the Sciatic N. of diabetic rats (Fig. $3 b$ ) supports the results of RIA for PA shown in Table I.

Fig. $3 c$ shows the S-100 immunoreactivity in the Sciatic N. of normal rats. S-100 is located in the cytoplasm of Schwann cells, but no significant difference was observed in its distribution and staining intensity when diabetic and nondiabetic subjects were compared (Fig. 3, $c$ and $d$ ).

\section{Discussion}

It has been reported that between 10 and $25 \%$ of diabetic patients have symptomatic neuropathy, which includes sensory impairment of peripheral nerves (20). Because $\mathrm{Ca}^{2+}$ is an important factor regulating cellular excitability and axonal transport in neurons (3-5), it is reasonable to postulate that an alteration of the levels of intracellular $\mathrm{Ca}^{2+}$ or $\mathrm{Ca}^{2+}$-binding proteins perturb the normal functions of the neurons.

Therefore, we investigated here the distribution of PA, $\mathrm{Ca}^{2+}$ binding neuronal marker protein, in the spinal cord and the peripheral nerve of normal rats. We found that PA exists only in the posterior root, suggesting that it contains fiber correlated with sensory nerve. In addition, we revealed by RIA that in diabetic peripheral nerves, the contents of PA significantly decreased as a function of time, while S-100 did not show any significant change. We confirmed immunohistochemically that the number of PA containing myelinated fibers was lower in diabetic nerves. Accordingly, the results suggest that the alteration of levels of PA in the peripheral nerves might contribute to the pathogenesis of diabetic neuropathy.

Although the role of PA in the neurons remains unclear, the information presented here provides a clue to clarifying the pathogenesis of diabetic neuropathy.

\section{References}

1. Cheung, W. Y. 1980. Calmodulin plays a pivotal role in cellular regulation. Science (Wash. DC). 207:19-23.

2. Bernard, B., G. L. Sottacase, G. Sandri, E. Carafoli, A. N. Taylor, T. C. Vanaman, and R. J. P. Williams. 1983. Calcium-binding Proteins. Elsevier Science Publishing Co., Amsterdam. 217-315.

3. Jakobsen, J., and P. Sidenius. 1979. Decreased axonal flux of ret- rogradely transported glycoprotein in early experimental diabetes. J. Neurochem. 33:1055-1060.

4. Meiri, K. F., and W. G. McLean. 1982. Axonal transport of protein in motor fibers of experimentally diabetic rats. Brain Res. 238:77-88.

5. Tomlinson, D. R. 1983. Axonal transport of noradrenaline, protein, and glycoprotein in cat hypogastric nerve in vitro under conditions of high extracellular glucose. Diabetologia. 24:172-178.

6. Siegel, F. W., E. Carafoli, R. H. Ketsinger, D. H. Maclennan, and R. H. Wasserman. 1980. Calcium-binding Proteins: Structure and Function, Elsevier/North-Holland, Amsterdam.

7. Heizmann, C. W., M. W. Berchtold, and A. M. Rowlerson. 1982. Correlation of parvalbumin concentration with relaxing speed in mammalian muscle. Proc. Nat. Acad. Sci. USA. 79:7243-7247.

8. Celio, M. R., and C. W. Heizmann. 1981. Calcium-binding protein parvalbumin as a neuronal marker. Nature (Lond.). 293:300-302.

9. Matus, A., and S. Mughal. 1975. Immunohistochemical localization of S-100 protein in brain. Nature (Lond.). 258:746-748.

10. Stefansson, K., R. L. Wollmann, and B. W. Moore. 1982. Distribution of S-100 protein outside the central nervous system. Brain Res. 234:309-317.

11. Endo, T., and H. Hidaka. 1983. Effect of S-100 protein on microtubule assembly-disassembly. FEBS (Fed. Eur. Biochem. Soc.) Lett. 161:235-238.

12. Haglid, K. G., H. A. Hansson, and L. Ronnback. 1970. S-100 in the central nervous system of rat, rabbit, and guinea pig during postnatal development. Brain Res. 123:331-345.

13. Endo, T., T. Tanaka, T. Isobe, H. Kasai, T. Okuyama, and H. Hidaka. 1981. Calcium-dependent affinity chromatography of S-100 and calmodulin on calmodulin antagonist-coupled Sepharose. J. Biol. Chem. 256:12485-12489.

14. Endo, T., K. Takazawa, and T. Onaya. 1985. Parvalbumin exists in rat endocrine glands. Endocrinology. 117:527-531.

15. Endo, T., K. Takazawa, S. Kobayashi, and T. Onaya. 1986. Immunochemical and immunohistochemical localization of parvalbumin in nervous tissues. $J$ : Neurochem. 46:892-898.

16. Hidaka, H., T. Endo, and K. Kato. 1983. Assay of S-100 protein by enzyme immunoassay. Methods Enzymol. 102:256-261.

17. Endo, T., M. Kobayashi, S. Kobayashi, and T. Onaya. 1986. Immunocytochemical and biochemical localization of parvalbumin in the retina. Cell Tissue Res. 243:213-217.

18. Hara, K., M. Ito, J. Takeuchi, S. Iijima, T. Endo, and H. Hidaka. 1983. Distribution of S-100 protein in normal salivary glands and salivary gland tumors. Virchows Arch. Pathol. Anat. Physiol. Klin. Med. 401: 237-249.

19. Sternberger, L. A. 1979. Immunohistochemistry. 2nd ed. John Wiley \& Sons, Inc., New York. 58-81.

20. Clements, R. S. 1979. Diabetic neuropathy. New concepts of its etiology. Diabetes. 28:604-611. 